COMUNICAÇÃO CIENTÍFICA

\title{
Efeito da safranina-azul de metileno na coloração dos oocistos de Cystoisospora felis (Wenyon, 1923) Frenkel, 1977 (Apicomplexa: Cystoisosporinae) ${ }^{\star}$
}

\section{Effect of safranin-metilene blue in the staining of Cystoisospora felis (Wenyon, 1923)Frenkel, 1977 oocysts (Apicomplexa: Cystoisosporinae)}

\author{
Patrícia Seibel Melo, ${ }^{\star \star}$ Simoni Machado de Medeiros, ${ }^{* \star \star}$ Carlos Wilson Gomes Lopes ${ }^{\star \star \star *}$
}

\begin{abstract}
Resumo
A técnica de coloração por safranina-azul de metileno é um método indicado para a identificação dos oocistos de Cystoisospora felis em esfregaços de fezes, devido a resolução, especificidade e sensibilidade da coloração às estruturas morfológicas. Amostras de fezes após serem identificadas como positivas para oocitos de $C$. felis foram coradas pela técnica da safraninaazul de metileno. Após a coloração, os oocistos foram identificados por suas estruturas morfológicas, onde os esporocistos e esporozoítas coraram-se em vermelho-rubi, em contraste com o citoplasma e parede dos oocistos, que mantiveram sua coloração original, sem modificar as características da espécie estudada.
\end{abstract}

Palavras-chave: Cystoisospora felis; oocistos; coloração; safranina-azul de metileno.

\begin{abstract}
The Safranin-Metilene Blue staining is a method specific and sensible definition for the diagnosis of $C$. felis oocysts. Fecal samples were previously indicated as positive for $C$. felis, were stained by Safranin-Metilene Blue. After staining, the oocysts were identified by their morphological structures, mainly sporocysts and sporozoites, which were stained in ruby-red while the cytoplasm and oocyst wall which maintained their original color, without changed morphological characteristics of the species studied.
\end{abstract}

Keywords: Cystoisospora felis; oocysts; stain; safranin-metilene blue.

A diarréia é clinicamente uma síndrome caracterizada por fezes líquidas ou semi-líquidas, em grande freqüência e quantidade, provocando, conseqüentemente, desidratação.

$\mathrm{Na}$ etiologia da diarréia incluem-se agentes infecciosos, parasitários, de natureza alimentar ou ambiental. Entre as causas parasitárias, observa-se a Cistoisosporose felina.

A cistoisosporose felina tem como agentes etiológicos as espécies Cystoisospora felis e C. rivolta, sendo caracterizada pela presença de oocistos nas fezes, ou ainda associados ao quadro clínico de diarréia e desidratação com a presença de formas evolutivas dos parasitos.

A técnica de coloração por safranina-azul de metileno descrita por Baxby et al. (1984) é, segundo estes autores, o método mais indicado para identificação de oocistos pois estes permanecem com medidas próximas às dos oocistos não corados. Esta técnica tem sido estudada para identificação de oocisto de Cyclospora e Cryptosporidium, e em ambos os casos obteve-se uma coloração uniforme, com boa sensibilidade e especificidade e bem detalhável. (Kang, Mathan, 1996, Smith et al., 1989 e Visvesvara et al., 1997). Amostras de fezes, de felinos naturalmente infectados, com oocistos de $C$. felis foram obtidas no município de Seropédica, Estado do Rio de Janeiro. Estas foram processadas da seguinte forma: diluídas em água destilada, filtradas através de tamis com gaze dobrada. O produto filtrado foi sedimentado em cálice de Hoffman por uma hora. O sedimento resultante foi fixado em formalina a $10 \%$. Uma amostra do material fixado foi centrifugada por três vezes consecutivas, por 10 minutos a $1.500 \mathrm{rpm}$. De cada centrifugação, se desprezou o sobrenadante e aproveitou-se o sedimento. Deste sedimento foram feitos esfregaços que, após de secos, eram fixados em metanol clorídrico a $3 \%$ por 3 a 5 minutos. Depois deste tempo, o esfregaço foi lavado em água corrente para, então,

\footnotetext{
* Sob os auspícios do CNPq.

** Curso de Medicina Veterinária e bolsista de Iniciação Científica (CNPq/UFRRJ-PIBIC).

*** Curso de Pós-Graduação em Medicina Veterinária-Parasitologia Veterinária da UFRRJ.

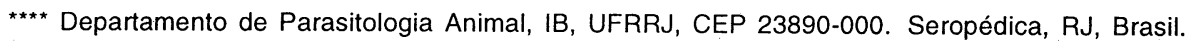


corar as lâminas com a solução de safranina. Durante esta coloração é necessário o uso de uma lamparina para aquecimento da solução de safranina. Se necessário, adicionase mais safranina à lâmina. A seguir, a lâmina foi lavada em água corrente, e então, coberta com a solução de azul de metileno por 1 minuto. A lâmina foi, então, lavada em água corrente. Os esfregaços, agora corados e secos, foram montados entre lâmina e lamínula com bálsamo de Canadá.

Os oocistos de $C$. felis (Figura 1), identificados nos esfregaços de fezes pela coloração safranina-azul de metileno, tiveram boa definição morfológica, com caracterização dos esporocistos e esporozoítas. Estas estruturas apresentaramse com coloração vermelho-rubi. Esta coloração veio a facilitar também no diagnóstico dos oocistos de $C$. felis em amostras fecais de felinos, prevenindo a quem as manuseia a contaminação com outros agentes etiológicos passíveis de serem transmitidos para humanos.

\section{Referências bibliográficas}

BAXBY, D., BUNDELL, N., HART, C.A. The development and performance of a simple sensitive method for the detection of Cryptosporidium oocysts in faeces. J. Hyg., v. 93, p. 317-323, 1984.

KANG, G., MATHAN, M. N. A comparison of five staining methods for detection of Cryptosporidium oocysts in faecal speciemens from the fied. Idian J. Med. Res., v. 103 p. 264-266, 1996.

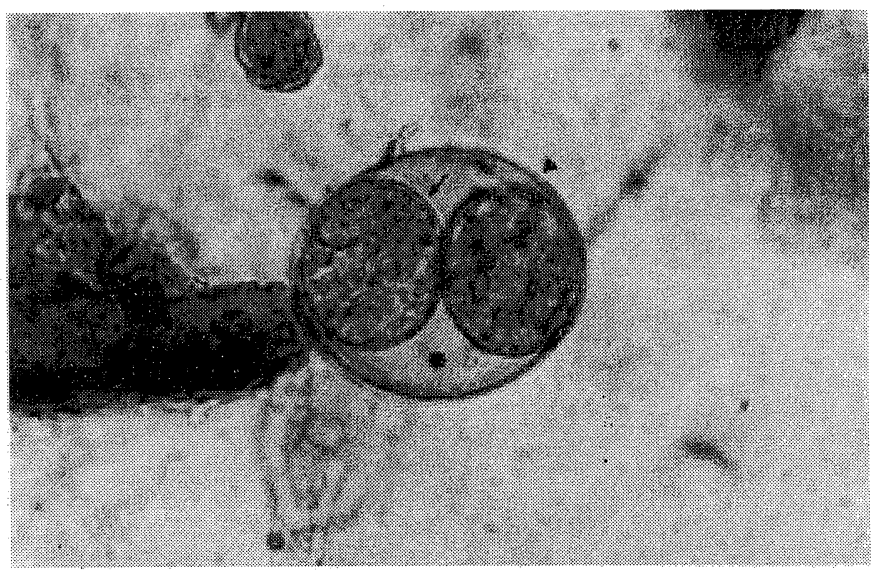

Figurà 1: Cystoisospora felis. Oocisto observado nas fezes de um gato. Esporocistos $(\rightarrow)$, esporozoítas ( $\star$ ), citoplasma (*) parede do oocisto (D). S-AM, 1000X.

SMITH, H.V., McDIARMID, A., SMITH, A.R.H., GILMOUR, R. A. An analysis of staining methods for detection of Cryptosporidium spp oocysts in water-related samples. Parasitology, v. 99, p.323327, 1989.

VISVESVARA, G. S., MOURA, H., KOVACS-NACE, E., WALACE, S., EBERHARD, M. L. Uniform staining of Cyclospora oocysts in faecal smears by a modified Safranin techinique with microwave heating. J. Clin. Microbiol., v. 35, p. 730-733, 1997. 